\title{
How a pricing decisions are decided and executed
}

\author{
Katarína Remeňová1,*, Jakub Kintler ${ }^{2}$ \\ ${ }^{1}$ University of Economics in Bratislava, Faculty of Business Management, Department of \\ Management, Dolnozemská 1/B, Bratislava, Slovakia \\ ${ }^{2}$ University of Economics in Bratislava, Faculty of Business Management, Department of Business \\ and Administration, Dolnozemská 1/B, Bratislava, Slovakia
}

\begin{abstract}
Marketing and management studies are rich in the theoretical backround related to price strategy and pricing. However, consistent with the lack of interest in complexity of decision making process in price management. The purpose of the research study is to identify all stages in decision - making process in price management in Slovak enterprises and to measure their mutual association and their dependence on elements of organizational parameters. Based on the results of descriptive statistics on decision making process in price management, we can say that companies go through an average of four steps in the decision-making process $(\mathrm{M}=$ $4.72)$, with higher variability $(\mathrm{SD}=3.02)$, compared to the mean.
\end{abstract}

\section{Introduction}

The need to define a decision-making process in price management has its roots in the firm's behavioral theory, which is based on decision-making processes in terms of the enterprise's production economy, focusing on how organizations make decisions about what process to follow in managing production and pricing. In the development of behavioral theory, pricing theory is emphasized as an equally important theory within the theories of the company. The decision-making process in price management (determination of price outputs and their changes) is placed within the nine-step decision-making process [1]. At the heart of behavioral theory by Cyert and March is the economic decision-making in terms of their process [2]. A special place in their work took the price setting topic as a decision - making process. The authors' research was focused on the development of process - oriented company models. Company decisions are viewed as well-defined behavioral steps [3].

Currently, only few scientific research studies about pricing is devoted to the decisionmaking process in price management. This issue has become the domain of businesses that must base price management on a formal decision-making process.

Decision making is concerned with evaluating and ranking possible alternatives of action [4]. Managerial decision making in pricing deals with decisions relating to setting or

\footnotetext{
* Corresponding author: katarina.remenova@euba.sk
} 
changing prices. Which includes price positioning and product decisions introducing new pricing points of products or service mix $[5,6]$.

Price management decision - making problems affect whole organization. Pricing decisions are made in a company based on overall marketing plan [7, 8, 9] because they influence their relationship with customers [10]. This topic is complex by the fact that there are various biases affecting the process of price setting within a company $[11,12,13]$. According to Smith [14] pricing is a continual process, that can't be done in isolation. Moreover, specialists in price management claim, that pricing should be seen as a process of deciding. Where the process must deliver the goal of making pricing decisions repeatedly and reliably, given the information. Some researchers perceive price management only through the optics of the price setting process, where they mention some steps of price management $[15,16,17,18]$.

\section{Methodology}

The purpose of the research study is to identify all stages in decision - making process in price management in Slovak enterprises and to measure their mutual association and their dependence on elements of organizational parameters. The statistical sample $(\mathrm{N}=250$ respondents) is comprised of managers operating in tactical and top management. The sample was created in PSPP by random selection. The researchers have ensured the measurement objectivity by using data collection tools in electronic form to prevent influencing the research subject. The participants were instructed in writing by one researcher. The observation survey was conducted using a questionnaire on the decisionmaking in price management.

Descriptive decision - making theory provides knowledge about decision-making, where the dominant topic is the decision-maker, with its approach to decision-making and the ability to assume the competence and responsibility to decide. In the research sample we observed the role of the respondent in the decision-making process in price management, namely in the implementation of the strategy. Most respondents define company's pricing strategy (46.53\%) and taking responsibility for its results. A third of the respondents have an impact on the performance of the strategy at the middle and top management level. Almost twenty-four percent of respondents have no influence on the definition and implementation of the pricing strategy (Table 1).

Table 1. Structure of respondents in terms of their impact on pricing and inclusion in the organizational structure.

\begin{tabular}{|r|r|r|r|}
\hline \multirow{2}{*}{ Level of impact on pricing } & Frequency & $\%$ & \multicolumn{1}{c|}{$\%$ cum. } \\
\cline { 3 - 4 } & & & \\
I define the price strategy & 114 & 46.53 & 46.53 \\
No impact on pricing & 58 & 23.67 & 70.20 \\
Implementation - middle level management & 46 & 18.78 & 88.98 \\
Implementation - top level management & 27 & 11.02 & 100.00 \\
\hline \hline
\end{tabular}

Source: own processing in PSPP

\subsection{Data analysys}


The data obtained through the questionnaire method are of a nominal and cardinal variable. Thus the type of the variable also made the selection of statistical methods conditional. Two-dimensional inductive statistics methods and methods of descriptive statistics were used to test the dependence of the nominal variables. The data were analyzed in PSPP statistical software. Hypotheses were tested at a significance level of $p \leq 0.05$; while maintaining the primary rule of the Chi-Square Test of Independece, where the theoretical frequencies did not fall below a value of 5 in $80 \%$, and for other values $\mathrm{X}>1$ applied.

\section{Results and Discussion}

Researchers have ensured the objectivity of measurement using data collected trough the on-line form of the secondary sources, that represent the financial statements, annual corporate reports and analysis of external entities. All variables represented interval or nominal data. Individual consultations and structured interviews with individual companies and researchers in the price management field led us to focus on selected areas of issue outlined in the final version of the questionnaire (in the pilot phase of the research). Therafter, we had proved the content validity and reliability of the research tool using Lawshe CVR for validity measurement [19]. Content validity was assessed using a panel of seven experts with professional expertise in the pricing. Based on the Likerts scale we had collected and analyzed their viewpoints on the relevance of the 18 questionnaire items to measure the construct defined by these items to ensure the content validity of the instrument [20]. For the assessment, the following scale was used: „1= the item isn't representative of revenue model“", ,2= the item needs major revisions to be representative revenue model“, , $3=$ the item needs minor revisions to be representative of revenue model“, „4=the items representative of revenue model".

The CVR of each item didn't decrease below the level of 0.7 and overall CVI reached the level of .95 . Thereby we had found this result representative.

The next step in the validation process of the questionnaire was to assess the reliability of our research tool. Overall the internal reliability measured by Cronbach's alpha reached the level of 0.71 , which were considered as acceptable.

\section{Decision - making steps in price management}

Decision making can be a one-time, mostly routine action or a process of progressive and logical steps, a so called decision making process. It is the most important part of decision making because it provides a normal progress of a company. We can define it as a collection of eight steps, starting with problem recognition and identification of criteria, then allocating weight to criteria, develop alternatives, analysis and selection of alternatives, implementation of the best alternative and finally evaluation of decision effectiveness.

Graph 1. Decision - making steps in price management. 


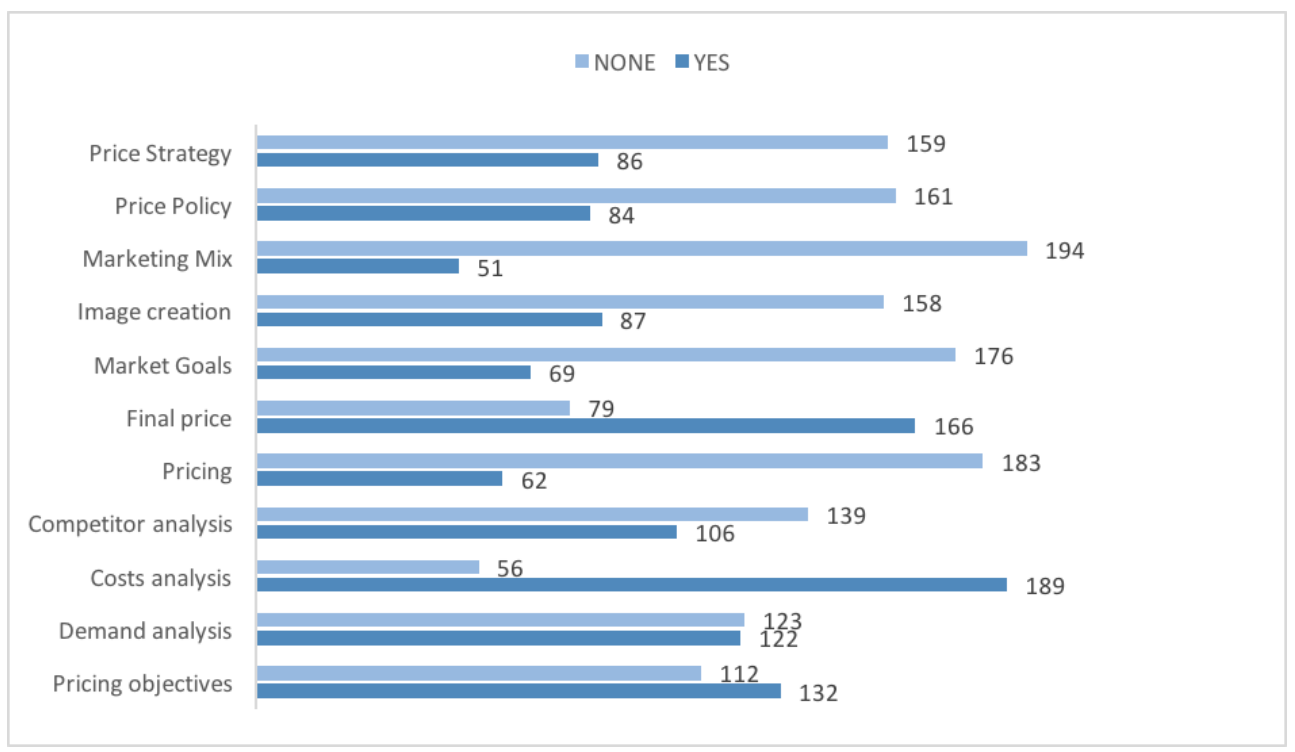

Source: own processing

Based on the results of descriptive statistics on decision making process in price management, we can say that companies go through an average of four steps in the decision-making process $(\mathrm{M}=4.72)$, with higher variability $(\mathrm{SD}=3.02)$, compared to the mean. The distribution normality was monitored through kurtosis and skewness. Based on the kurtosis data, which actually describes the shape of a data distribution $\mathrm{K}=-.33$, which corresponds to platykurtic distribution. The skewness also points to the non normal distribution of data in the decision-making process with skeweness $=.82$, which means, that score on the left arise from low point responses.

Table 2. Descriptive table for Number of steps in decision making process in price management

\begin{tabular}{|c||r|r|r|r|r|r|r|r|r|}
\hline Variable & $N$ & Mean & $\begin{array}{c}\text { Std } \\
\text { Dev }\end{array}$ & Variance & Skewness & Kurtosis & Range & Min & Max \\
\hline \hline No. of steps & 245 & 4.72 & 3.02 & 9.14 & .82 & -.33 & 10.00 & 1.00 & 11.00 \\
\hline
\end{tabular}

Source: own processing in PSPP

Another fundamental obstacle to an effective decision-making process in price management is its organization. The individual steps of the decision-making process ensure different functional areas of the company without a central coordinating element, often in the absence of a clear concept of price strategy. In the following graph we present a view of individual functional areas of control with the competence to define the price strategy or its implementation at various levels of management. Based on the results of the analysis, in less than $62 \%$ of these, the pricing strategy is dealt with by the marketing department, which includes product management and sales. Only $15.5 \%$ of respondents who are also CEOs or business owners declare that they are responsible for defining a pricing strategy. 
Graph 2. Impact on price management by functional areas of control

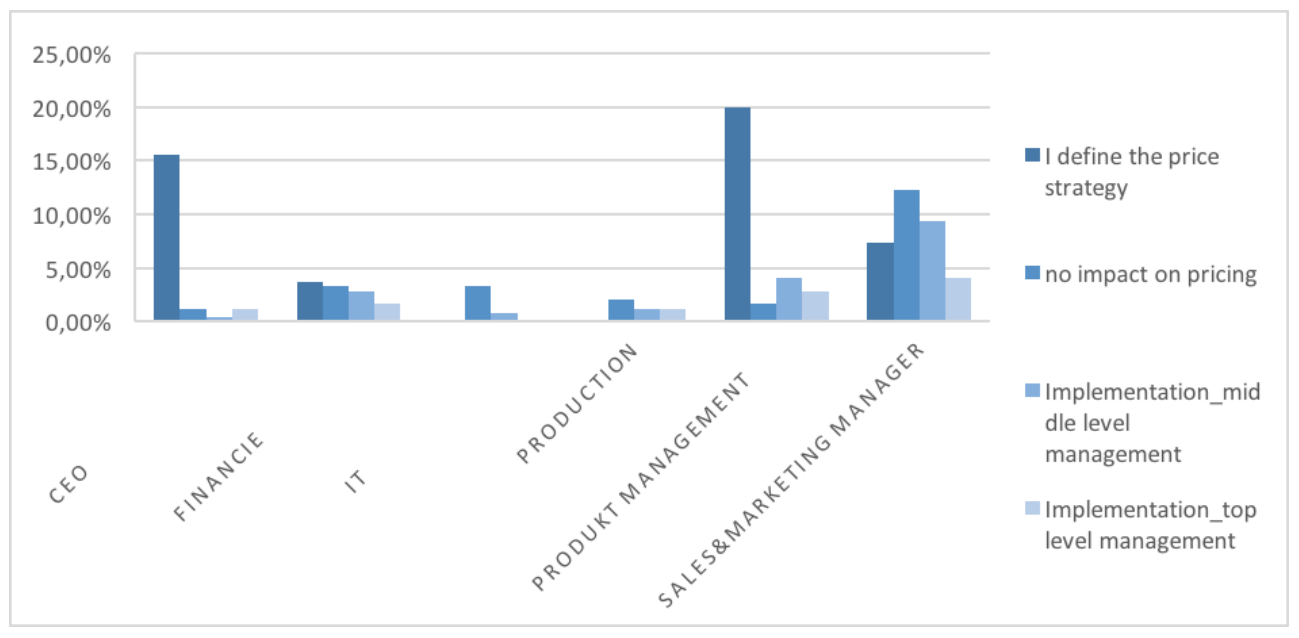

Source: own processing

\section{Conclusion}

Decision-making process in price management many researchers and entrepreneurs identify with the process of price setting. However, it is only a thread of the decisionmaking process in price management. The survey in small, medium and large companies operating on the Slovak market was carried out in order to identify and formalize the decision-making process in price management. The entrepreneurial view of price management is different and the individual steps of the process are limited to product pricing. Two key reasons for this are: lack of knowledge and experience in the price management of Slovak managers and the individual threads are divided in different organizational units.

The decision-making process in price management in Slovak companies is not unambiguously formalized, mainly due to insufficient information of the decision-makers. Its phases are applied in a non-sequential manner and many are omitted in the process. Rather, businesses benefit from a simplified pricing process focused on a cost-oriented approach, without the price optimization. These are small companies that do not have the necessary knowledge or the staffing capacity of specialists.

The most important stages in the decision-making process are for companies "Cost analysis" and "Setting final price".

The authors acknowledge that this paper is the partial result of the project VEGA No.: 1/0017/20 Changes in the application of managerial functions in the context of the fourth industrial revolution and adaptation processes in Slovakia for financial support to carry out this research. 


\section{References}

1. K. A. Cyert, G.March, Models in a behavioral theory of the firm. Pittsburg: Carnegie institute of technology (1959)

2. G. Schanz, Grundlagen der verhaltenstheoretischen Betriebswirtschaftslehre. Tůbingen : Deutsches Forschungsgemeintschaft, (1977)

3. R.M. Cyert, G. March, Behavioral Theory of the Firm. Milano: Wiley-Blackwell, (1992)

4. B. Malakooti, Decision making process: typology, intelligence, and optimization. Journal of intelligent manufacturing, 23(3), 733-746 (2012)

5. T.J Smith, Pricing Strategy. Mason: Cengage Learning, (2012)

6. S. Liouzu, The Pricing Journey. The Organizational Transformation Toward Pricing Excellence. Stanford: Stanford Business Books, (2015)

7. G.R. Foxall, The logic of price decision - making. Management Decision, 18(5), 235245 (2007)

8. Ch.Homburg, O. Jensen, A. Hahn, How to Organize Pricing? Vertical Delegation and Horizontal Dispersion of Pricing Authority. Journal of Marketing, 76(5), 49-69 (2012)

9. L. Sha, T. Fan, Research on Pricing Decision-Making for Fresh Agricultural Products with Strategic Customers and Value Decreasing Rate. 2ND international conference on sustainable energy and environmental engineering, DEStech Transactions on Environment Energy and Earth Sciences, Proceedings Paper, Xiamen, (2016)

10. Y. Polo, F.J. Sese, Strengthening Customer Relationships: What Factors Influence Customers to Migrate to Contracts? Journal of service research, 16(2), 138-154 (2013)

11. A. Hinterhuber, Violations of rational choice principles in pricing decisions. Industrial marketing management, 47, 65-74 (2015)

12. M. Carricano, Pricing myopia: do leading companies capture the full value of their pricing strategies? Management decision, 52(1), 159-178 (2014)

13. W. Georges, R. W. McGee, Analytical Contribution Accounting: The Interface of Cost Accounting and Pricing Policy. Greenwood Publishing Group, (1987)

14. T.J. Smith, Pricing Done Right: The Pricing Framework Proven Successful by the World's Most Profitable Companies. Hoboken: John Wiley \& Sons (2016)

15. T. T. Nagle, J. Hogan, J. Zale, The Strategy and Tactics of Pricing: New International Edition. Oxon: Routledge, (2016)

16. S. L. Barber, L. Lorenzoni, P. Ong, Price Setting and Price Regulation in Health Care. Paris: OECD Publishing, (2019)

17. J. Ronen, Y. Varda, Earnings Management: Emerging Insights in Theory, Practice, and Research. Vienna: Springer Science \& Business Media (2008)

18. S. Liozu, A. Hinterhuber, The ROI of Pricing: Measuring the Impact and Making the Business Case. Oxon: Routledge, (2014)

19. C.Ayere, A. J. Scally, Critical Values for Lawshe's Content Validity Ratio: Revisiting the Original Methods of Calculation. Measurement and Evaluation in Counseling and Development, 47(1), 79-86 (2014)

20. A.P. Singun, Heuristics as Mental Shortcuts in Evaluating Interactive Systems. International Journal of Engineering Pedagogy, 8(4), 143-152 (2018) 